Revista Destaques Acadêmicos, Lajeado, v. 10, n. 1, 2018. ISSN 2176-3070

DOI: http://dx.doi.org/10.22410/issn.2176-3070.v10i1a2018.1708

http://www.univates.br/revistas

\title{
CONFIANÇA EM EMPRESAS FAMILIARES: UM METAESTUDO EM TOP JOURNALS ENTRE 2000 E 2016
}

\author{
Denise Casagrande da Rocha ${ }^{1}$, Gabriel Machado Braido², \\ Bernardete Bregolin Cerutti ${ }^{3}$
}

\begin{abstract}
Resumo: Este artigo busca verificar o que foi publicado sobre confiança em estudos de empresas familiares nos principais journals da Administração no período entre 2000 e 2016, analisando as abordagens teóricas e metodológicas utilizadas. Para alcançar estes objetivos, foi realizado um metaestudo por meio da análise de 23 artigos sobre a temática publicados em journals de alto fator de impacto na área da Administração, indicados por pesquisadores especialistas. Observou-se que a confiança não vem sendo analisada como principal objetivo em grande parte dos estudos em empresas familiares. Quanto às abordagens teóricas, identificou-se que a maioria dos estudos não está embasado em teorias e, aqueles que estão, utilizam predominantemente as Teorias da Agência, Institucional e Stewardship. No que se refere às abordagens metodológicas, há a predominância de estudos qualitativos, sendo a pesquisa documental a técnica de coleta de dados mais utilizada. Destaca-se, também, a utilização de dados secundários para realização das pesquisas em 73,91\% dos estudos analisados. Por fim, com base nas lacunas apresentadas nos artigos, são apresentadas 7 sugestões de estudos, visando ao desenvolvimento das pesquisas sobre confiança em empresas familiares.
\end{abstract}

Palavras-chave: Confiança. Empresas familiares. Metaestudo.

1 Doutoranda em Administração (PPGAdm/Unisinos) e Mestre em Administração (PPGA/ EA/UFRGS). É diretora Executiva da Denise Casagrande - Desenvolvimento de Pessoas e Organizações. denise@denisecasagrande.com.br

2 Doutorando em Administração (PPGAdm/Unisinos) e Mestre em Administração (PPGA/ EA/UFRGS). É professor assistente da Universidade do Vale do Taquari - Univates. gabrielb@univates.br

3 Doutoranda em Desenvolvimento Regional (PPGDR/Unisc) e Mestre em Ambiente e Desenvolvimento (PPGAD/Univates). E professora assistente da Universidade do Vale do Taquari - Univates. bcerutti@univates.br 


\section{INTRODUÇÃO}

Em um contexto mundial de intensa competitividade e caracterizado por complexas mudanças, a questão da confiança emerge como um elemento relevante e que, de maneira abrangente, coloca-se como condição prévia para o estabelecimento e adição de valor às relações sociais, influenciando na satisfação, no trabalho e no desempenho organizacional.

Neste contexto, os estudos sobre confiança, inicialmente oriundos da área da psicologia, tiveram um enfoque mais individual da temática (DEUTSCH, 1962; GABARRO, 1978). Em continuidade, diversos estudiosos contribuíram para a ampliação das bases teóricas vigentes, acrescentando ao debate a análise dos aspectos intrínsecos à natureza da confiança, tendo em vista as dimensões interpessoal e organizacional correlatas (ZUCKER, 1986).

No que tange às pesquisas sobre empresas familiares, observa-se que embora a histórica existência de empresas constituídas por famílias, este tema passou a ser tratado com algum formalismo acadêmico somente após os anos 60, por iniciativa de estudiosos interessados em compreender melhor as particularidades deste tipo de arranjo produtivo, o que foi fortalecido posteriormente pela criação do Family Firm Institute (FFI), em 1986, e o periódico Family Business Review, em 1988 (SHARMA; CHRISMAN; GERSICK, 2012).

Embora desde então já tenham ocorrido importantes avanços nesta trajetória, percebe-se que os temas correlatos a empresas familiares ainda carecem de reconhecimento como integrantes de uma disciplina independente, suficientemente robusta para caracterizar um campo acadêmico (STEWART; MINER, 2011). Em verdade, ao utilizar-se de teorias de outras disciplinas acadêmicas para explicar os fenômenos típicos das empresas familiares, os pesquisadores acabam não se apropriando suficientemente das questões pertinentes a este campo de pesquisa, oferecem contribuições acanhadas para o desenvolvimento de teorias próprias e, como consequência, reafirmam o relativo atraso desta construção, tendo em vista as demandas do contexto de negócios (BIRD et al., 2002).

A investigação da confiança de empresas familiares tem sua relevância destacada por Sundaramurthy (2008), ao afirmar que a confiança é fundamental neste tipo de organização, onde um grupo de indivíduos está filiado com a empresa e conectado através de ancestralidades comuns ou casamentos, e a sua existência vai muito além da simples lógica econômica. Neste sentido, entendese que aproximar os estudos de confiança e de empresas familiares representa uma oportunidade real de compartilhamento de ideias, discussões teóricas e aplicadas e, sobretudo, reforça o amadurecimento destas respectivas áreas de pesquisa.

Durante a década de 1990, o campo de produção científica em Administração teve um aumento significativo na quantidade de publicações gerando uma análise crítica que objetivou apurar a qualidade, o rigor, a 
relevância e a originalidade das diversas pesquisas publicadas na área (CALDAS; TONELLI; LACOMBE, 2002), bem como se estas pesquisam avançam, de fato, no conhecimento considerando as lacunas e as oportunidades apontadas por estudos anteriores (SOUZA; REINERT; SPROSSER, 2009, SUDARAMURTHY, 2008). Diante disso, surgiram os metaestudos que se multiplicaram principalmente nas áreas de organizações, marketing, sistemas de informação, administração pública e produção, analisando as mais diversas dimensões da produção científica em cada uma dessas áreas (CALDAS; TONELLI; LACOMBE, 2002).

Considerando este contexto e a necessidade de sistematizar a produção científica acerca da confiança em estudos sobre empresas familiares, definiu-se como problema de pesquisa a seguinte questão: o que vem sendo publicado sobre confiança em estudos de empresas familiares nos principais journals da Administração? Para responder a esta questão, foram estabelecidos os seguintes objetivos: (i) verificar o que foi publicado sobre confiança em estudos de empresas familiares no período entre janeiro de 2000 e junho de 2016; (ii) analisar quais são as abordagens teóricas e metodológicas utilizadas nesses estudos; e (iii) apresentar sugestões de pesquisas futuras a partir das lacunas identificadas nos artigos analisados.

Para a realização desta investigação, foram analisadas as publicações de 5 journals de relevância (Top Journals) para a área de Administração, conforme a indicação de dois pesquisadores especialistas nas áreas de gestão e confiança nas organizações, que são: Academy, Family Business Review, Organization Studies, Journal of Management Studies e Administrative Science Quarterly.

Este artigo está organizado em quatro capítulos, além deste introdutório, sendo: a revisão de literatura, no capítulo 2, seguido pelos procedimentos metodológicos, no capítulo 3, apresentação e discussão dos resultados, no capítulo 4, e, concluindo, as considerações finais, no capítulo 5. Ao final, são apresentadas as referências consultadas.

\section{REVISÃO DE LITERATURA}

\subsection{Confiança}

Estudiosos e pesquisadores contemporâneos de diferentes áreas (psicologia, sociologia, economia, gestão e organização), ao debater sobre confiança, referem-se a autores seminais (Durkheim, Simmel e Freud entre outros) que, de diferentes maneiras e conforme os seus campos de conhecimento e os seus domínios teóricos, aprofundaram o entendimento sobre esta temática (MOLLERING, 2001).

Em continuidade aos estudos de referência, outros autores com suas distintas visões, avançam no sentido de compor esse complexo mosaico acadêmico, trazendo significativas contribuições teóricas sobre o tema 
confiança. Nessa trajetória, Williamson (1993) abordou a confiança em uma perspectiva mais concreta e calculada, enquanto que North (1990) e Zucker (1986) corroboram com uma visão mais institucional. Deutsch (1962), Rotter (1967) e Tyler (1990), por sua vez, enfocam os atributos psicológicos e cognitivos dos atores e analisam o impacto destes na expressão da confiança nas suas relações, enquanto que Granovetter (1985) conferiu à análise uma perspectiva voltada para a incorporação de aspectos sociais às relações interpessoais e interorganizacionais.

Para Robinson (1994), a confiança está fundamentada sobre as expectativas, crenças ou suposições dos indivíduos, de que dentro de uma perspectiva futura as ações dos outros lhes serão positivas e favoráveis ou, pelo menos, não lhes serão negativas ou nocivas aos seus interesses pessoais. Fukuyama (1996) também fundamenta a confiança, sobre a lógica do manejo das expectativas, porém com um enfoque coletivo, onde as expectativas são inerentes a uma comunidade, caracterizada como regular, honesta e cooperativa, e cuja a interação e funcionamento baseiam-se em normas e princípios comuns aos participantes.

Já a abordagem de Rousseau et al. (1998, p. 395) acrescenta a dimensão da vulnerabilidade das interações pessoais e define confiança como um "[...] estado psicológico, onde o indivíduo está predisposto a aceitar essa vulnerabilidade implícita, tendo em vista expectativas de caráter positivo e benéfico quanto as intenções e ao comportamento dos outros".

Destaca-se, ainda, pelo menos três conceituações básicas sobre confiança, relacionadas às vertentes das Teorias Econômica, Social e Organizacional respectivamente: para as Teorias Econômicas (agência e custos de transação), o indivíduo é compreendido como um ator racional e suas escolhas estão relacionadas às oportunidades de maximizar ganhos de utilidade racionalmente definidos, o que implica sempre em algum nível de risco decorrente.

Deste modo, conforme Luhmann (1979) e Coleman (1990), confiança implica na decisão subjacente ao risco, uma vez que as trocas sempre envolvem transferência de recursos entre os atores, bem como o atendimento às expectativas e aos interesses implícitos a estes. Os comportamentos são, portanto, modelados pela racionalidade e pelo oportunismo dos atores, tendo em vista os seus objetivos, resultando na chamada "confiança calculada" (LANE; BACHMANN, 2002).

Do ponto de vista das Teorias Sociológicas, para Simmel (1950), confiança é uma força potente que funciona para os indivíduos, propagando-se através destes e que ao mesmo ampliando-se por meio das associações humanas em geral. Dentro dessa lógica é possível pensar que a confiança se estabelece em diferentes níveis, que variam conforme o contexto social, o objeto da confiança ou o estágio de relacionamento alcançado pelas partes envolvidas. 
Möllering (2001) aponta que, para Simmel (1950), a confiança é algo que transcende a racionalidade ou a cognição humana e que envolve um elemento quase religioso e associado a fé, dito como um "salto de fé". Em continuação, para ele a sociedade existe a partir de trocas sociais e essas não são possíveis sem que exista confiança. Nesta ótica é possível pensar-se a confiança como algo que antecede e precede o conhecimento e se configura exatamente como um estágio entre o conhecimento e a ignorância do indivíduo (MOLLERING 2001), bem como trata-se de uma composição entre sentimentos e racionalidade (LEWIS; WEIGERT, 1985).

Luhmann (1979), ainda com base nas proposições teóricas de Simmel (1950), aborda a confiança como um mecanismo cuja função é reduzir a complexidade social na qual os indivíduos estão inseridos. Para tanto, ele distingue dois tipos de confiança: (1) confiança pessoal/interpessoal e (2) confiança no sistema/organização propriamente dita.

Em linha com a abordagem das Teorias Organizacionais, diferencia-se duas dimensões de confiança: (1) confiança cognitiva; (2) confiança afetiva; Costa (2000), por sua vez, acrescenta à análise uma terceira dimensão: (3) confiança comportamental. A confiança cognitiva baseia-se na crença racional de que, por princípio, o indivíduo é confiável e competente, bem como auxilia a distinguir de maneira mais objetiva, indivíduos e instituições passíveis de receber a confiança alheia. Já a confiança afetiva, baseia-se na ligação emocional, cuidado e preocupação mútua entre os atores, nas suas trocas sociais. A dimensão afetiva, mais do que a dimensão cognitiva, parece ser chave para o engajamento e comprometimento dos funcionários com os propósitos organizacionais (WILLIAM, 2001). Por fim, a confiança comportamental referese à expressão na prática das duas dimensões anteriores (COSTA, 2000).

Mesmo considerando os distintos "olhares" presentes nestes estudos, bem como a variedade de significados atribuídos ao conceito de confiança, alguns pressupostos são compartilhados pelos especialistas: (1) existe interdependência entre "quem confia" e "quem recebe a confiança"; (2) a confiança é uma alternativa para lidar com o risco ou incerteza nas relações de troca; (3) a confiança é uma crença ou uma expectativa de que a vulnerabilidade resultante da aceitação de risco não será usada na relação pela outra parte (LANE; BACHMANN, 2002).

\subsection{Confiança nas organizações}

A reflexão sobre confiança organizacional remete ao entendimento das relações estabelecidas em uma lógica formal e conforme as perspectivas (1) interna (nível de confiança estabelecido entre funcionários e a organização e vice e versa) e (2) externa (nível de confiança estabelecido entre clientes, fornecedores, acionistas e a sociedade em geral com a organização e vice e versa). As duas perspectivas são construídas com base na cultura interna e 
no posicionamento de mercado da empresa, bem como no modo com que se relaciona com os funcionários e demais públicos de interesse, com os processos operacionais e com as tecnologias adotadas.

Complementarmente, o conceito de confiança organizacional referese à confiança estabelecida entre indivíduos ou grupos na organização, considerando esta como uma entidade que possui características e identidade próprias. Não se trata, portanto, da mesma confiança que se tem nos indivíduos de modo particular, mas sim na confiança que se tem na organização de maneira mais ampla e completa. A confiança organizacional pode ser entendida, não como o resultado da adição das partes ou fragmentos (indivíduos ou grupos) pertencentes a organização, mas como resultado da potencialização destes com vistas a criação da correspondente confiabilidade organizacional, que pode ser estendida e percebida nas relações interorganizacionais ou mesmo entre as organizações e as partes interessadas.

A confiabilidade organizacional, na perspectiva moral, trata dos aspectos positivos ou virtuosos de uma organização (não do conjunto dos seus representantes) que explicitam o mérito em ser considerada confiável interna e externamente. A introdução da perspectiva moral é, portanto, distintiva para o entendimento da confiança organizacional, uma vez que amplia as perspectivas cognitiva e afetiva exploradas anteriormente por meio de diversos estudos (CALDWELL; CLAPHAM, 2003). Além disso, possibilita a análise mais profunda sobre a "essência" da organização e o quanto essa singularidade influencia o relacionamento com os públicos de interesse e cria valor interno e externo para os envolvidos.

Nesta perspectiva, é fundamentada nos comportamentos e nas mensagens implícitas à organização, o posicionamento dos líderes, pois constitui uma poderosa fonte de confiança e de propósito para indivíduos e equipes (KRAMER, 1999; WEICK, 1979). Esse movimento acaba por criar e reforçar um ciclo virtuoso, onde quanto maior for o nível de confiança interno na organização, maior será a possibilidade de cooperação entre os envolvidos e vice e versa, de modo que a expectativa de ação reforça o alcance dos resultados desejados (PUTNAM, 1993).

Estudiosos ao longo dos anos têm investido no desenvolvimento de tipologias e metodologias que ajudem a avançar com a literatura a respeito da confiança organizacional, tanto interna como externamente. Nessa direção, destaca-se a tipologia da confiança desenvolvida por Luhmann (1979) e, posteriormente, revisitada e estendida por Zucker (1986), onde são propostas 3 bases de fundamentação para o conceito: (1) Confiança baseada em processos (refere-se ao histórico cumulativo de processos, trocas e de relacionamentos estabelecidos entre os diferentes atores); (2) Confiança baseada em características (refere-se ao compartilhamento das semelhanças étnicas e culturais, de valores e normas entre os atores e (3) Confiança baseada na instituição (refere-se ao reconhecimento formal das estruturas sociais). 


\subsection{Empresas familiares}

É consenso que a empresa ou negócio familiar típico caracteriza-se como uma organização de propriedade familiar, normalmente controlada por integrantes da família (SHANKER; ASTRACHAN, 1996; LANSBERG, 1999) e que por vezes transcende diferentes gerações de herdeiros (ANDERSON; REEB, 2003; GOMEZ-MEJIA et al., 2007).

Empresa familiar é, portanto, um negócio baseado em uma sociedade sustentável, potencialmente transgeracional, que é gerido formalmente, por membros de uma mesma família ou de um pequeno número de famílias, que trazem consigo uma visão implícita do seu ramo familiar sobre o negócio (SHARMA; CHRISMAN; CHUA, 1997).

Neste sentido, a empresa familiar envolve a conjugação de características, dinâmicas e expectativas implícitas entre 2 dimensões complementares: a família e o negócio (FLEMONS; COLE, 1992; GERSICK et al., 1997;), exigindo soluções diferenciadas quanto à gestão da estrutura societária e de propriedade, da governança corporativa e do planejamento de sucessão, especialmente para os integrantes da família que atuam no negócio (CHRISMAN; CHUA; SHARMA, 1999; CHRISMAN; CHUA; STEIER, 2003).

Somente a questão da propriedade de um negócio por uma ou mais famílias não é suficiente para caracterizá-lo como uma empresa familiar. Para tanto, é necessário adicionar a esta o envolvimento da família proprietária na gestão, bem como a visão compartilhada entre os integrantes sobre o potencial de benefícios que a empresa poderá gerar para a família através das gerações (BENNEDSEN; PEREZ-CONZALEZ; WOLFENZON, 2010; CHUA; CHRISMAN; SHARMA, 1999). Como os integrantes da família que atuam na empresa, em geral, dispõem de maior liberdade para agir unilateralmente, do que ocorreria em empresas não familiares (CARNEY, 2005), o comportamento das empresas familiares é distintamente influenciado pelos valores e pelas metas não-econômicas da família, bem como pelo seu envolvimento e compromisso emocional com o negócio e geração de riquezas econômicas e sócio emocionais para a família (GÓMEZ-MEJÍA et al., 2007).

\section{PROCEDIMENTOS METODOLÓGICOS}

Para a elaboração dessa pesquisa, inicialmente foram selecionados os artigos que abordaram a temática de confiança em estudos sobre empresas familiares. Para tanto, foram seguidas as etapas de seleção de artigos propostas por Dresch, Lacerda e Antunes (2015), as quais são apresentadas na sequência.

\section{Etapa 1 - Definição do tema ou questão de pesquisa}

Definiu-se como problema a seguinte questão: o que vem sendo publicado sobre confiança em estudos de empresas familiares nos principais 
journals da Administração? Neste sentido, por meio da realização deste metaestudo, pretende-se aprofundar os conhecimentos sobre o tema, bem como recolher evidências sobre a evolução das pesquisas nesta temática, analisando abordagens teóricas e metodológicas, principais assuntos abordados e lacunas para pesquisas futuras.

\section{Etapa 2 - Busca dos estudos existentes}

Foram definidos os periódicos que serviram de base para busca dos artigos analisados, adotando como critérios de seleção a relevância e o impacto dos mesmos na área de Administração. Para isso, foram consultados 2 pesquisadores especialistas, ambos com doutorado em Administração e diversas publicações em periódicos nacionais e internacionais, que indicaram os seguintes veículos: Academy, Family Business Review, Organization Studies, Journal of Management Studies e Administrative Science Quarterly.

Para a seleção dos artigos, consultou-se as páginas dos periódicos onde foi realizada uma busca avançada dos termos "trust" AND "family business" nos resumos e títulos dos artigos, no período entre janeiro de 2000 e junho de 2016. Como este filtro retornou com poucos resultados, optou-se por realizar a busca dos termos em todo o texto, mantendo o mesmo intervalo de tempo e termos de busca, o que resultou em um número maior de artigos localizados. Esta busca ocorreu no dia 28 de junho de 2016 e identificou-se um total de 121 artigos, sendo: 50 artigos no Journal of Management Studies; 39 artigos na Academy; 18 artigos no Organization Studies; 9 artigos na Family Business; e 5 artigos no Administrative Science Quarterly.

\section{Etapa 3 - Seleção dos estudos para integrar a pesquisa}

Nesta etapa foram analisados todos os resumos e palavras-chave dos artigos selecionados, a fim de identificar aqueles de fato relacionados à temática de confiança em empresas familiares, procedendo também a exclusão de notas de editores, call for papers e artigos do Academy of Management Perspective $e$ Executive, por não apresentarem o formato de artigos científicos que desejavase analisar.

Como a busca anterior foi pelos termos "trust" e "family business" em todo o texto, observou-se que diversos artigos apresentavam estes termos ao longo da redação, mas não possuíam este foco de análise. Dessa forma, foi necessário analisar artigo por artigo, a fim de identificar se o termo confiança era foco do estudo e/ou somente coadjuvante ou resultado do do mesmo.

Buscando diminuir a subjetividade e os vieses na seleção dos artigos pela análise do resumo, esta foi realizada individualmente pelos autores e, na sequência, os resultados foram confrontados. Os casos de discrepância foram separadamente analisados, buscando posteriormente o consenso sobre a 
manutenção ou exclusão do artigo. Após esta análise, foram selecionadas 23 publicações que compõem a amostra deste estudo.

Os periódicos analisados, juntamente com o número de artigos encontrados na primeira seleção (amostra inicial) e os artigos que permaneceram após análise da Etapa 3 (amostra final), foram: Academy (Journal e Review), 39 iniciais e 6 finais, representando $15,38 \%$ da amostra inicial; Administrative Science Quarterly, 5 iniciais e 3 finais, representando 60,00\%; Family Business Review, 9 iniciais e 8 finais, representando 88,89\%; Journal of Management Studies, 50 iniciais e 1 final, representando 2,00\%; e Organization Studies, 18 iniciais e 5 finais, representando $27,78 \%$.

Observa-se que foi possível aproveitar apenas 19,01\% dos artigos obtidos na primeira análise, com destaque positivo para o Family Business Review, onde $88,89 \%$ dos artigos se enquadraram na amostra, possivelmente por ser um periódico específico de estudos em empresas familiares.

\section{Etapa 4 - Avaliação da relevância e da qualidade dos estudos selecionados}

Para a avaliação da relevância dos estudos selecionados, adotouse a verificação do Fator de Impacto, no Journal Citation Reports, do Web of Knowledge, de cada periódico onde os artigos foram publicados, bem como a leitura completa do artigo para verificar se ele se enquadrava no escopo desejado para a pesquisa. Os periódicos e seus respectivos Fatores de Impacto JCR são: Academy of Management Journal = 6.233; Academy of Management Review = 7.288; Journal of Management Studies = 4.260; Family Business Review = 4.147; $\mathrm{e}$ Organization Studies $=2.798$.

Observa-se que todos os periódicos analisados apresentam fator de impacto considerável para a área de Administração, com valores entre 2.798 (Organization Studies) e 6.233 (Academy of Management Journal), o que comprova a qualidade destes periódicos de acordo com o critério de seleção.

\section{Etapa 5 - Discussão dos resultados obtidos}

Para a discussão dos resultados, entre as várias técnicas de síntese que podem ser empregadas em análises de literatura, utilizou-se a abordagem de metaestudo, que de acordo com Hocayen-da-Silva et al. (2008), permite a classificação dos procedimentos metodológicos, do referencial teórico, do número de autores por artigos, entre outras informações relevantes, viabilizando conclusões a respeito dos campos de conhecimento ou da produção de uma área de estudos como um todo.

Assim, este estudo recolheu evidências nos artigos selecionados contemplando os 3 componentes de análise propostos por Dresch, Lacerda e Antunes (2015), que são: metadados, metamétodo e metateoria. A análise de metadados é essencialmente interpretativa e tem o objetivo de identificar similaridades e discrepâncias entre os estudos, em termos de fenômenos 
descritos, enquanto que o metamétodo analisa as abordagens metodológicas em seus diversos aspectos, e a metateoria pressupõe a análise dos pressupostos teóricos dos estudos selecionados (DRESCH; LACERDA; ANTUNES, 2015).

\section{APRESENTAÇÃO E DISCUSSÃO DOS RESULTADOS}

\subsection{Análise de metadados}

Inicialmente, buscou-se analisar a autoria dos artigos, onde foi possível observar que 49 diferentes autores assinaram as publicações analisadas, sendo que destes autores, apenas 4 (Alexandra Dawson, Daniel Hjorth, Lai Si TsuiAuch e Luis R. Gómez-Mejia) possuem 2 publicações, enquanto que os outros 45 possuem apenas um artigo.

A quantidade de autores por artigo variou entre 1 e 4 , sendo que a média foi de 2,26 autores por artigo. Identificou-se, ainda, que 6 artigos tiveram única autoria, 7 foram escritos por 2 autores, 8 artigos por 3 e outros 2 têm a assinatura de 4 autores.

Quanto à quantidade de publicações por ano, o histórico do número de artigos desde o ano 2000 até 2016 é de 23 artigos, o que representa uma média de 1,35 artigos publicados ao ano. Destaca-se que o auge de publicações ocorreu no ano de 2005, com 4 artigos e no ano de 2007, com 3 artigos. Duas publicações foram identificadas ao longo de 4 anos (2008, 2012, 2015 e 2016). Ao longo de oito anos (2000, 2001, 2002, 2003, 2004, 2010, 2011 e 2014) apenas um artigo foi publicado e em outros 3 anos $(2006,2007$ e 2013) nenhuma publicação foi localizada.

Apesar da presença dos temas confiança e empresa familiar em todos os artigos analisados, buscou-se entender melhor como o debate sobre confiança se apresenta neste contexto. Para tanto, realizou-se uma verificação nos artigos, por meio da análise das respectivas palavras-chave, abstracts e tópicos gerais contidos na estrutura e nos referenciais teóricos dos estudos. Esta análise resultou na identificação de nove diferentes abordagens sobre confiança nas empresas familiares, sendo: Confiança organizacional (presente em 7 artigos); Confiança na governança corporativa (presente em 7 artigos); Confiança institucional (presente em 5 artigos); Confiança na gestão da empresa (presente em 4 artigos); Confiança nas relações familiares (presente em 4 artigos); Confiança nas relações interpessoais (presente em 3 artigos); Confiança na sucessão (presente em 2 artigos); Confiança no mercado (presente em 1 artigo); e Confiança nas redes especializadas (presente em 1 artigo).

Vale ressaltar que alguns artigos foram enquadrados em mais de uma dimensão, portanto a frequência total de ocorrências extrapola o número total de artigos analisados. Os resultados apurados revelam uma visão geral de como o tema da confiança está sendo tratado no campo das empresas familiares, bem 
como as áreas de interesse dos autores ao longo de mais de uma década de estudos.

No geral, tendo em vista os artigos analisados, fica evidente que o tema da confiança em empresas familiares, é pouco abordado de maneira direta e explícita pelos autores, sendo que somente 2 artigos tratam da confiança como objeto principal de estudo. Verifica-se, portanto, que o tema é subjacente às temáticas centrais desenvolvidas nestes artigos e é abordada pelos autores a partir das diferentes dimensões relacionadas: confiança nas relações interpessoais, organizacional, na gestão da empresa, na governança corporativa, nas redes especializadas, nas relações familiares, no mercado, institucional e na sucessão.

Atualmente, mesmo considerando-se a relevância e a complementariedade dos temas relacionados à gestão de empresas familiares de maneira mais ampla, os temas de confiança na organização (propriamente dita, incluindo processos e práticas) e na governança corporativa são os mais explorados nos artigos analisados. Além disso, embora a confiança na gestão da empresa e a confiança nas relações familiares sejam dimensões relacionadas e que podem influenciar principalmente a confiança na governança corporativa, verifica-se que estas ainda não foram suficientemente examinadas. A confiança no mercado e a confiança nas redes especializadas, por sua vez, são as perspectivas menos presentes nos estudos, sendo mencionadas apenas em 1 artigo cada.

\subsection{Análise de metateoria}

Nesta etapa verificou-se que 12 artigos (52,17\%) não utilizaram abordagens teóricas para seu embasamento, enquanto que os outros $11(47,83 \%)$ utilizaram 10 abordagens teóricas distintas, as quais são descritas no item 4.1. Vale ressaltar que alguns artigos utilizam uma combinação de abordagens teóricas em suas análises, fato que justifica a frequência total de 20 utilizações de abordagens nos 11 artigos analisados.

A variedade de teorias utilizadas nestes artigos sugere o interesse dos pesquisadores em abordar a perspectiva das empresas familiares a partir de "diversas lentes teóricas", mas ao mesmo tempo demonstra a inexistência de teorias específicas voltadas para esta disciplina e reafirma a necessidade dos estudiosos utilizarem teorias de outros campos para embasar as pesquisas nesta área, conforme já haviam constatado Bird et al. (2002).

A Teoria da Agência embasou 5 pesquisas, o correspondente a $25 \%$ do total de artigos que utilizaram alguma lente teórica. Sob esta perspectiva, a gestão organizacional orienta-se para constituição de uma organização eficiente, caracterizada pelo equilíbrio na relação entre o agente e o principal, informações e riscos (EISENHARDT, 1989) e pela administração de questões relacionadas 
à agência (relações entre os investidores e os gestores) e a discricionariedade diretiva (comportamentos oportunistas dos gestores) (EISENHARDT, 1985).

Deste modo, em se tratando de empresas familiares, a Teoria da Agência oferece também subsídios importantes para o melhor entendimento do contrato e do compromisso entre administradores e proprietários, bem como do desempenho e da confiança implícita entre ambos (HENDRIKSEN; VAN BREDA, 1999).

A Teoria Institucional, que também foi utilizada em 5 estudos, preocupase com a forma como as organizações protegem e melhoram as suas posições e a sua legitimidade, em conformidade com as regras e normas estabelecidas no ambiente institucional (MEYER; ROWAN, 1991). Neste contexto, o termo "instituição" refere-se aos conjuntos formais de regras e acordos que as organizações e os indivíduos devem seguir (BRUTON; AHLSTRON; LI, 2010), as quais são derivadas de regras como as estruturas reguladoras, órgãos governamentais, leis, profissões e outras práticas sociais e culturais que exercem pressões de conformidade (DiMAGGIO; POWELL, 1983).

Quando os atores acreditam na adequação de uma prática e a julgam como legítima, são motivados a adotá-la e institucionalizá-la; contudo, quando duvidam, muitas vezes a consideram como não legítima e, assim, são motivados a rejeitá-la. Dessa forma, a compreensão de como os argumentos formam e refletem as crenças é fundamental para explicar a adoção e institucionalização de práticas, porque a aquisição, manifestação, ou mudança de crenças molda a formação e a evolução das decisões de legitimidade, que, por sua vez, molda os atores das decisões institucionais para adotar ou rejeitar certas práticas (HOEFER, GREEN JR., 2016).

A Stewardship Theory, lente teórica que embasou 3 estudos, utiliza-se de conceitos da sociologia e da psicologia para oferecer uma visão alternativa onde os atores organizacionais veem uma maior utilidade em relacionamentos de longo prazo do que em comportamentos oportunistas de curto prazo (HERNANDEZ, 2012). A autora ainda complementa que, nesta perspectiva, os melhores interesses a longo prazo são colocados à frente dos objetivos e interesses pessoais que servem apenas para interesses individuais. Esta abordagem, ao contrário da Teoria da Agência, entende que as motivações dos gestores e proprietários estão alinhadas com os objetivos do negócio e, portanto, não existe oportunismo e não há a necessidade de contratos rigorosos e controle nas operações e relações, aumentando a confiança existente nos relacionamentos.

Em se tratando de estudos sobre empresas familiares e considerando toda a complexidade envolvida neste tipo de arranjo societário, a Stewardship Theory parece útil para explicar o alinhamento de expectativas, objetivos e resultados entre os integrantes da família (perspectiva de longo prazo e de perenidade da empresa) ou entre estes e os executivos de mercado que trabalham na empresa (perspectiva de mais curto prazo). A questão da 
confiança em empresas familiares, portanto, parece ser decorrente também da consistência destes alinhamentos e longevidade dos alinhamentos internos.

Estas 3 teorias apresentadas serviram de embasamento teórico para $65 \%$ dos estudos analisados, enquanto que as demais abordagens teóricas - Socioemotional Selectivity Theory (SEST), Teoria da Confiança, Teoria da Dependência de Recursos (RDV), Teoria da Identidade, Teoria da Tomada de Decisões, Teoria de Identidade Social e Teoria de Rede foram utilizadas apenas em uma pesquisa cada, o correspondente a $5 \%$.

Diante desses resultados, constata-se que não existe uma teoria clássica dominante nos estudos sobre confiança em empresas familiares, haja vista que contextos e objetivos muito específicos têm sido investigados (conforme relatado na seção de análise de metadados), o que dificulta a adoção de uma única teoria para embasamento dos estudos.

\subsection{Análise do metamétodo}

Inicialmente foram identificadas as abordagens utilizadas, observando uma tendência à realização de pesquisas qualitativas, visto terem sido realizadas em $60,87 \%$ dos artigos, enquanto que as pesquisas quantitativas representaram apenas $39,13 \%$ dos estudos. Vale destacar que, na amostra investigada, não foram encontrados estudos que tenham utilizado abordagens mistas, ou seja, aplicação de procedimentos metodológicos qualitativos e quantitativos em 1 mesma pesquisa.

Acredita-se que a preferência por este tipo de pesquisa na investigação acerca da confiança em estudos de empresas familiares justifica-se pela novidade do tema e pela necessidade de um entendimento maior no campo, sendo necessária a condução de pesquisas exploratórias mais aprofundadas a respeito. Roesch (2009) complementa que embora busquem o que é comum, as pesquisas qualitativas mantêm-se abertas para entender os significados e a singularidade que cada indivíduo atribui à realidade.

Após, buscou-se verificar quais foram as técnicas de coletas de dados mais utilizadas pelos autores nestas pesquisas. É possível observar 5 diferentes técnicas de coletas de dados utilizadas nos artigos, sendo: Pesquisa documental em 18 artigos, representando 69,23\%; Entrevistas em 4 artigos, representando 15,38\%; Survey em 2 artigos, representando 7,69\%; Observações em 1 artigo, representando 3,85\%; e Análise narrativa também em apenas 1 artigo, representando 3,85\%. Observa-se 26 utilizações no total, o que permite afirmar que alguns dos artigos valeram-se de mais de uma técnica de coleta de dados. Cabe ressaltar, ainda, que dos 23 artigos analisados, 8 (34,78\%) classificamse como teóricos, propondo framezorks ou modelos a partir de revisões de literatura.

É notória a predominância de artigos utilizando a pesquisa documental como técnica de coleta de dados $(69,23 \%)$, o que pode ser justificado pelos 
objetivos de pesquisa propostos pelos autores, bem como pela dificuldade de acesso direto às empresas pesquisadas, o que é bastante comum em se tratando de empresas familiares. Além disso, em vários artigos a questão central era a análise da confiança nas relações contratuais (à luz da Teoria da Agência) e do desempenho econômico-financeiro das empresas, o que justifica a respectiva análise de documentos, englobando uma série de contratos e relatórios (especialmente de perfil, econômico-financeiros e de resultados) das organizações.

A entrevista também foi utilizada em 4 estudos (15,38\%), os quais desejavam obter informações mais aprofundadas da realidade das empresas familiares, o que não seria possível simplesmente a partir da análise de documentos. Dessa forma, os pesquisadores entrevistaram gestores e/ou funcionários das organizações a fim de recolher evidências que permitissem uma análise mais rica da situação. Por fim, tanto as observações quanto as análises narrativas foram utilizadas, cada uma, em 1 único estudo.

Um ponto que chama a atenção refere-se à baixa utilização de questionários do tipo survey para coleta de dados, pois embora nove estudos analisados tenham sido classificados como quantitativos, apenas 2 deles utilizaram os questionários como instrumento de coleta de dados. A partir desta observação, buscou-se verificar o percentual de utilização de dados de origem primária e secundária, onde identificou-se que apenas $26,09 \%$ dos estudos coletaram dados primários para a realização das pesquisas, enquanto que $73,91 \%$ valeram-se de dados secundários em suas análises.

Constata-se, portanto, uma tendência para a utilização de dados provenientes de relatórios e arquivos das empresas, os quais são trabalhados de forma quantitativa, como auxílio as técnicas estatísticas, para realização deste tipo de estudo.

\subsection{Sugestões de estudos futuros}

A partir da análise das limitações e das indicações para pesquisas futuras dos artigos analisados, observou-se que, em termos gerais, um número expressivo de artigos aponta como limitações de pesquisa a dificuldade de generalização dos achados, sugerindo que as conclusões e modelos teóricos propostos sejam validados, considerando amostras maiores, bem como a adoção de maior rigor metodológico e a replicação das pesquisas em contextos de diferentes culturas.

Acredita-se que esta evolução não pode restringir-se ao estudo estático destes fenômenos ou mesmo ao estudo dos integrantes da família e de suas relações, da organização propriamente dita ou ainda das questões societárias envolvidas neste tipo de empresa (SHARMA, 2004). É preciso ir além e tratar destes aspectos de forma integrada e co-evolutiva, reforçando o entendimento 
entre a dinâmica das relações familiares e dos negócios, caminho este que ainda precisa ser percorrido pelos pesquisadores (STEWARD; MINER, 2011).

Deste modo, analisando as limitações e lacunas apontadas pelos autores, são propostas 7 questões de pesquisas que poderiam ser respondidas em novos estudos a fim de evoluir as pesquisas sobre confiança em empresas familiares, as quais são: (1) Quais são as variáveis envolvidas no estabelecimento da confiança e qual a relação destas com o sucesso das empresas familiares?; (2) Qual a correlação existente entre confiança e cultura em empresas familiares?; (3) Como se estabelece a confiança na governança corporativa? Será que o desejo da família de se manter à frente da empresa influencia os níveis de confiança na gestão dos públicos de interesse?; (4) A confiança na organização é causa ou efeito da confiança na governança corporativa em empresas familiares?; (5) Tensões e conflitos entre os gestores familiares e os gestores não-familiares: como preservar a confiança mútua?; (6) Conselhos de Administração como alternativa para garantir a sobrevivência organizacional através das transições geracionais: mito ou realidade?; (7) A confiança na governança corporativa em empresas familiares é impactada pelas transições de gerações?

Para corroborar com a importância das sugestões de pesquisa propostas, o journal Organization Studies (top jornal em Administração), recentemente fez uma chamada de artigos para uma edição especial com foco em Family Business Research: Exploring the Multilevel Complexity of Family Organization, onde a questão da confiança encontra-se implícita.

\section{CONSIDERAÇÕES FINAIS}

Por meio do problema de pesquisa, este artigo estabeleceu-se três objetivos. O primeiro buscou verificar o que foi publicado sobre confiança em estudos sobre empresas familiares no período entre janeiro de 2000 e junho de 2016. Embora em uma primeira análise tenha sido possível identificar 121 artigos, observou-se que, na realidade, estudos específicos analisando a confiança em empresas familiares são raros, sendo que a confiança tem aparecido como coadjuvante ou resultado dos estudos, e não como foco de análise.

O segundo objetivo buscou analisar quais são as abordagens teóricas e metodológicas utilizadas nos estudos. Observou-se que 52,17\% dos estudos não utilizaram teorias em suas análises, enquanto que os demais foram conduzidos à luz de 10 diferentes abordagens, com destaque para a Teoria da Agência e Teoria Institucional, utilizadas em 5 estudos cada, e a Stewardship Theory, utilizada em 3 estudos.

No que se refere às abordagens metodológicas, identificou-se a predominância de estudos qualitativos, o que indica que os pesquisadores estão mais interessados em entender em profundidade os fenômenos investigados ao invés de buscar generalizações a partir da aplicação de pesquisas tipo survey. 
Outro aspecto metodológico que chamou a atenção refere-se à grande utilização de pesquisas documentais e de dados secundários para a realização dos estudos, fato que pode ser justificado pela dificuldade de acesso as informações primárias das empresas, o que é comum em se tratando de empresas familiares, além da necessidade de verificação de documentos como contratos, relatórios econômico-financeiros das organizações, entre outros para a realização das análises propostas nos estudos.

O terceiro objetivo consistiu em apresentar sugestões de pesquisas futuras a partir das lacunas identificadas nos artigos analisados, de modo a contribuir para o maior entendimento do tema da confiança, bem como para ampliar e consolidar o campo da empresa familiar.

Acredita-se que os objetivos estabelecidos foram alcançados, no entanto, o estudo apresenta algumas limitações que devem ser destacadas, como o fato do mesmo ter focado somente em publicações nos periódicos Academy, Family Business Review, Organization Studies, Journal of Management Studies e Administrative Science Quarterly. Embora esta escolha tenha sido proposital, sugere-se a realização da mesma pesquisa em bases de dados como Web of Knowledge, EBSCO, entre outras, a fim de identificar o que vem sendo publicado sobre a temática de maneira global. Também seria interessante a realização da pesquisa em revistas e eventos brasileiros, buscando identificar o que vem sem pesquisado sobre este tema em nível nacional.

Por fim, espera-se que este artigo seja uma contribuição para os pesquisadores interessados na temática de confiança em empresas familiares, apresentando um panorama da evolução do campo, das pesquisas já realizadas, bem como apontando alguns direcionamentos para pesquisas futuras.

\section{REFERÊNCIAS}

ANDERSON; R. C.; REEB, D. Founding-Family Owner and Firm Performance: Evidence from the S\&P500. Journal of Finance, v. 58, p. 1302-1328, 2003.

BENNEDSEN, M.; PÉREZ-GONZALEZ, F; WOLFENZON, D. Do CEOs Matter? Working Paper. Columbia and Stanford University, 2010.

BIRD, B. et al.. Family business research: The evolution of an academic field. Family Business Review, v. 15, n. 4, p. 337-350, 2002.

BRUTON, G. D.; AHLSTRON, D.; LI, H.L. Institutional Theory and Entrepreneurship: Where Are We Now and Where Do We Need to Move in the Future?

Entrepreneurship Theory and Practice. v. 34, p. 421-440, 2010.

CALDAS, M. P.; TONELLI, M. J.; LACOMBE, B. M. B. Espelho, Espelho Meu: Meta-estudo da Produção Científica em Recursos Humanos nos ENANPADs da Década de 90. In: Encontro da Associação Nacional de Pós-Graduação e Pesquisa em Administração, 2002, Anais... ANPAD, 2002. 
CALDWELL, C.; CLAPHAM, S. E. Organizational trustworthiness: An international perspective. Journal of Business Ethics, v. 47, 349-358, 2003.

CARNEY, M. Corporate governance and competitive advantage. Entrepreneurship Theory and Practice, v. 29, n. 3, 249-26, 2005.

CHIRICO, F.; SALVATO, C. Knowledge Integration and Dynamic Organizational Adaptation in Family Firms. Family Business Review, v. 21, n. 2, p. 169-181, 2008.

CHRISMAN, J. J; CHUA, J.H; SHARMA, P. Defining the Business by Behavior. Entrepreneurship: Theory and Pratice, 1999.

CHRISMAN, J. J; CHUA, J.H.; STEIER, L. An introduction to theories of family business, Journal of Business Venturing, p. 441-448, 2003.

CHUA, J. H.; CHRISMAN, J. J.; SHARMA, P. Defining the family business by behavior. Entrepreneurship Theory and Practice, v. 23, n. 4, p. 19-39, 1999.

COLEMAN, J. S. The Foundations of Social Theory. Cambridge, Mass.: Harvard University Press, 1990

COSTA, A. C. A confiança nas organizações: um imperativo nas práticas de gestão. In: S. B. RODRIGUES \& M. P. CUNHA (Orgs.), Estudos organizacionais: novas perspectivas na administração de empresas: uma coletânea luso-brasileira. São Paulo: Iglu, 2000.

DE MASSIS, A. et al. Family Business Studies: An annotated bibliography. Edward Elgar Publishing Inc, 2012.

DEUTSCH, M. Cooperation and trust: some theoretical notes. In M. Jones (Ed.), Nebraska symposium on motivation. Lincoln, NE: University of Nebraska Press, 1962.

DiMAGGIO, P. J.; POWELL, W. W. The Iron Cage Revisited: Institutional Isomorphism and Collective Rationality in Organizational Fields. American Sociological Review. v. 48, p. 147-160, 1983.

DRESCH, A., LACERDA, D.P., ANTUNES, J.A.V. Design Science Research: Método de pesquisa para avanço da ciência e tecnologia. São Paulo, Bookman, 2015.

EISENHARDT, K. Agency Theory: An Assessment and Review. The Academy of Management Review, v. 14, n. 1, p. 57-74, 1989.

EISENHARDT, K. Control Organizacional and Economic Approaches. Management Science, v. 31, p. 134-139, 1985.

FLEMONS, D. G.; COLE, P. M. Connecting and separating family and business: A relational approach to consultation. Family Business Review. v. 5, n. 3, p. 257-269, 1992. 
FUKUYAMA, F. Confiança: As virtudes sociais e a criação da prosperidade. p. 51, 1. ed, Rio de Janeiro: Rocco, 1996.

GABARRO, J. The development of trust, influence and expectations. In A. Athos \& J. Gabarro (Eds.), Interpersonal behavior. Englewood Cliffs, NJ: Prentice Hall, 1978.

GERSICK, K.E. et al. Generation to generation: Life cycles of the family business. Boston: Harvard Business School Press, 1997.

GIDDENS, A. Central Problems in Social Theory: Action, Structure and Contradiction in Social Analysis. Berkeley, CA: University of California Press, 1979.

GÓMEZ-MEJÍA, L. R. et al. Socioemotional Wealth and Business Risk in FamilyControlled Firms: Evidence from Spanish Olive Oil Mills. Administrative Science Quarterly. v. 52, n. 1, p. 106-137, 2007.

GRANOVETTER, M. Economic Action and Social Structure: The problem of Embeddedness. American Journal of Sociology, v. 91, p. 481-510, 1985.

HENDRIKSEN, E.S.; VAN BREDA M.F. Teoria da Contabilidade. São Paulo: Atlas, 1999.

HERNANDEZ, M. Toward an understanding of the psychology of stewardship. Academy of Management Review, v. 37, n. 2, p. 172-193, 2012.

HOEFER, R. L.; GREEN JR., S. E. A rhetorical model of institutional decision making: the role of rhetoric in the formation and change of legitimacy judgments. Academy of Management Review, v. 41, n. 1, p. 130-150, 2016.

KRAMER, R. M. Trust and distrust in organizations: emerging perspectives, enduring questions. Annual Review of Psycology, New York, v. 50, p. 569-598, 1999.

LANE, C.; BACHAMANN, R. (Eds), Trust Within and Between Organizations:

Conceptual Issues and Empirical Applications, Oxford University Press, Oxford. 1998.

LANSBERG, I. Succeeding generations: Realizing the dream of families in business. Cambridge: Harvard Business School Press, 1999.

LEWIS, J. D.; WEIGERT, A. Trust as a social reality. Social Forces, v. 63, p. 967-985, 1985.

LUHMANN, N. Trust and Power. Chichester: John Wiley, 1979.

MALHOTRA, N. K. Pesquisa de marketing: uma orientação aplicada. 6.ed. Porto Alegre: Bookman, 2012.

MAYER, R., DAVIS, J., \& SCHOORMAN, F. An integrative model of organizational trust. Academy of Management Review, v. 20, n. 3, 709-734, 1995. 
MEYER, J. W.; ROWAN, B. Institutionalized Organizations: Formal Structure as Myth and Ceremony, in The New Institutionalism in Organizational Analysis. Eds. W. W. Powell and P. J. DiMaggio. Chicago: University of Chicago Press, p. 41-62, 1991.

MOLLERING, G. The nature of trust: from Georg Simmel to a theory of expectation, interpretation and suspension. Sociology, v.35, n.2, p. 403-420, 2001

NORTH, D. C. Institutions, Institutional Change, and Economic Performance. Cambridge: Cambridge University Press, 1990.

OLIVEIRA, A. F.; TAMAYO, A. Confiança do empregado na organização. In M. M. M. Siqueira (Org.), Medidas do comportamento organizacional: ferramentas de diagnóstico de gestão. Porto Alegre: Artmed Bookman, 2008.

PUTNAM, R.D., Making Democracy Work: Civic Traditions in Modern Italy. Princeton: Princeton University Press, 1993.

ROBINSON, A. Spirituality and risk: toward an understanding. Holist Nurse Pract, v. 8, n. 2, p. 1-7, 1994.

ROESCH, S. M. A. Projetos de estágio e de pesquisa em administração: guia para estágios, trabalhos de conclusão, dissertações e estudos de caso. 3. ed. São Paulo: Atlas, 2009

ROTTER, J.B. Interpersonal Trust, Trustworthiness and Gullibility, American Psychologist, v. 35, p. 1-7, 1980.

ROUSSEAU, D. M.; SITKIN, S. B.; BURT, R. S.; CAMERER, C. Not so different after all: A crossdiscipline view of trust. Academy of Management Review, v. 23, p. 393404, 1998.

SHANKER, M.C.; ASTRACHAN, J.H. 1996. Myths and realities: family business's contribution to US economy - A framework for assessing family business statistics, Family Business Review, v. 9, n. 2, p. 107-123, 1996.

SHARMA, P. An overview of the field of family business studies: Current status and directions for the future. Family business review, v. 17, n. 1, p. 1-36, 2004.

SHARMA, P.; CHRISMAN, J. J.; CHUA, J. H. Strategic management of the family business: Past research and future challenges. Family Business Review, 10, 1-36, 1997.

SIMMEL, G. The Sociology of Geeorge Simmel. ed K.H.Wolff. New York: Free Press, 1950.

SOUZA, S. A. de; REINERT, J. N.; SPROSSER, R. L. Pesquisa brasileira em Administração: um meta-estudo em temáticas do período 2000-2009. In: II Encontro de Ensino e Pesquisa em Administração e Contabilidade, 2009, Anais... ANPAD, 2009. 
STEWARD, A.; MINER, A.S. The Prospects for Family Business in Research universities. Journal of Family Business Strategy, v. 2, p. 3- 14, 2011.

SUNDARAMURTHY, C. Sustaining trust within family businesses. Family Business Review, n. 21, n. 1, p. 89-102, 2008.

WEICK, K. E. Social psychology of organization. São Paulo: Edgard Blücher, EDUSP, 1979.

WILLIAM, M. In whom we trust: Group membership as an affective context for trust development, Academy of Management Review, v. 26, n. 3, p. 377-396, 2001

WILLIAMSON, Oliver E. Calculativeness, Trust and Economic Organization. Journal of Law and Economics, v. 36, n. 2, p. 453-486, 1993.

ZUCKER, L. G. Production of trust: Institutional sources of economic structure.

Research in Organizational Behavior, v. 8, p. 53-111. 1986. 